\title{
Recent progress towards development of effective systemic chemotherapy for the treatment of malignant brain tumors Hemant Sarin
}

\author{
Address: National Institute of Biomedical Imaging and Bioengineering, National Institutes of Health, Bethesda, Maryland, USA \\ Email: Hemant Sarin - sarinh@mail.nih.gov
}

\author{
$\begin{array}{ll}\text { Published: I September } 2009 & \text { Received: } 5 \text { August } 2009\end{array}$ \\ Journal of Translational Medicine 2009, 7:77 doi:10.1186/1479-5876-7-77 \\ Accepted: I September 2009
}

This article is available from: http://www.translational-medicine.com/content/7///77

(c) 2009 Sarin; licensee BioMed Central Ltd.

This is an Open Access article distributed under the terms of the Creative Commons Attribution License (http://creativecommons.org/licenses/by/2.0), which permits unrestricted use, distribution, and reproduction in any medium, provided the original work is properly cited.

\begin{abstract}
Systemic chemotherapy has been relatively ineffective in the treatment of malignant brain tumors even though systemic chemotherapy drugs are small molecules that can readily extravasate across the porous blood-brain tumor barrier of malignant brain tumor microvasculature. Small molecule systemic chemotherapy drugs maintain peak blood concentrations for only minutes, and therefore, do not accumulate to therapeutic concentrations within individual brain tumor cells. The physiologic upper limit of pore size in the blood-brain tumor barrier of malignant brain tumor microvasculature is approximately 12 nanometers. Spherical nanoparticles ranging between $7 \mathrm{~nm}$ and $10 \mathrm{~nm}$ in diameter maintain peak blood concentrations for several hours and are sufficiently smaller than the $12 \mathrm{~nm}$ physiologic upper limit of pore size in the blood-brain tumor barrier to accumulate to therapeutic concentrations within individual brain tumor cells. Therefore, nanoparticles bearing chemotherapy that are within the 7 to $10 \mathrm{~nm}$ size range can be used to deliver therapeutic concentrations of small molecule chemotherapy drugs across the blood-brain tumor barrier into individual brain tumor cells. The initial therapeutic efficacy of the Gd-G5doxorubicin dendrimer, an imageable nanoparticle bearing chemotherapy within the 7 to $10 \mathrm{~nm}$ size range, has been demonstrated in the orthotopic RG-2 rodent malignant glioma model. Herein I discuss this novel strategy to improve the effectiveness of systemic chemotherapy for the treatment of malignant brain tumors and the therapeutic implications thereof.
\end{abstract}

\section{Background}

Malignant brain tumors consist of high-grade primary brain tumors such as malignant gliomas[1], and metastatic lesions to the brain from peripheral cancers such as lung, breast, renal, gastrointestinal tract, and melanoma[2,3]. Glioblastoma, the highest grade of malignant glioma, is the most common high-grade primary brain tumor in adults $[4,5]$. Overall, metastatic brain tumors are the most common brain tumors in adults, as $10 \%$ to $20 \%$ of patients with a malignant peripheral tumor develop brain metastases[2,3,6]. Even though malignant gliomas are generally treated with a combina- tion of surgery, radiotherapy and systemic chemotherapy $[7,8]$, and metastatic brain tumors with a combination of surgery and radiotherapy [9-11], the overall long-term prognosis of patients with these tumors, whether primary or metastatic, remains poor. Patient median survival times typically range between 3 and 16 months [12-16], and the percentage of patients alive at 5 years ranges between 3\% and $10 \%[12,13,16,17]$. In the treatment of both malignant gliomas and metastatic brain tumors, surgery and radiotherapy are more effective when used in combination[7-11,18-20]. In the treatment of malignant gliomas, there some minimal additional benefit of systemic chem- 
otherapy $[8,15,20-27]$; and in the treatment of metastatic brain tumors, it remains unclear as to if there is any additional benefit of systemic chemotherapy[9,10,28-31].

Systemic chemotherapy consists of small molecule chemotherapy drugs $[8,32]$ that are drugs of molecular weights (MW) less than $1 \mathrm{kDa}$ and diameters less than 1 to $2 \mathrm{~nm}$. These small molecule chemotherapy drugs include traditional drugs that target the cell cycle, for example, DNA alkylating drugs, and newer investigational drugs that target cell surface receptors and associated pathways, for example, tyrosine kinase inhibitors $[8,32]$. The ineffectiveness of these chemotherapy drugs in treating malignant brain tumors has been attributed to the blood-brain barrier (BBB) being a significant impediment to the transvascular extravasation of drug fraction across the barrier into the extravascular compartment of tumor tissue[29,33-35]. However, the pathologic BBB of malignant brain tumor microvasculature, also known as the blood-brain tumor barrier (BBTB), is porous[36,37]. Contrast enhancement of malignant brain tumors on MRI is due to the transvascular extravasation of Gd-DTPA (Magnevist, MW 0.938 $\mathrm{kDa}$ ) across the pores in the BBTB into the extravascular extracellular compartment of tumor tissue $[38,39]$.

\section{Historical strategies to improve the effectiveness of systemic chemotherapy}

Historically, two different strategies have been employed in the effort to improve the effectiveness of small molecule systemic chemotherapy in treating malignant brain tumors, although neither strategy has been particularly effective. The first strategy has been to elevate small molecule drug concentrations within the extravascular extracellular compartment of tumor tissue. One approach to this strategy has been the use of lipophilic small molecule drugs for increased permeation of drug fraction across endothelial cells of the ВBTВ[40,41]. The effectiveness of this approach has been limited due to drug binding to plasma proteins[42], in addition to the efflux of a significant proportion of extravasated drug fraction back into systemic circulation by BBTB multi-drug resistance pumps such as p-glycoprotein[35,43]. Other approaches to this strategy include the administration of drugs intra-arterially to maximize first-pass drug delivery across the BBTB [44-46], and the temporary opening of the junctions between endothelial cells of the BBTB to enhance the permeation of drugs across the $\mathrm{BBTB}[34,47,48]$. The overall ineffectiveness of these approaches can be attributed to the fact that there is only a transient elevation in drug concentrations within extravascular extracellular compartment of tumor tissue due to the short blood half-life of small molecule chemotherapy [49-55], which precludes the accumulation of drug fraction to therapeutic concentrations within individual brain tumor cells.
The second strategy has been to increase the blood halflife of small molecule chemotherapy. One approach to this strategy has been the intravenous co-administration of labradimil (RMP-7, Cereport), a metabolically stable bradykinin $\mathrm{B} 2$ receptor agonist, during the intravenous administration of small molecule chemotherapy drugs such as carboplatin. Although the co-administration of labradimil increases the blood half-life of small molecule chemotherapy drugs [56-59], the increase in drug blood half-life is temporary[60], which again, precludes the accumulation of drug fraction to therapeutic concentrations within individual brain tumor cells. Another approach to this strategy has been the use of continuous chemotherapy dosing schemes[61,62]. The potential effectiveness of this approach, however, has been limited by the systemic toxicity associated with it, which is due to the non-specific accumulation of small molecule drugs within normal tissues, as these drugs are small enough to permeate across endothelial barriers of normal tissue microvasculature [61-64].

In more recent years, slow sustained-drug release formulations of small molecule chemotherapy drugs have been developed by the non-covalent attachment of chemotherapy drugs to polymers or the encapsulation of drugs within liposomes[65,66]. Such nanoparticle-based drug release formulations are intravascular free drug reservoirs with long blood half-lives, since these spherical nanoparticles generally range between $30 \mathrm{~nm}$ and $200 \mathrm{~nm}$ in diameter [67-69], and are significantly larger than the physiologic upper limit of pore size in the BBTB of malignant brain tumor microvasculature. Since nanoparticlebased drug release formulations remain intravascular within brain tumor microvasculature, free drug is slowly released into systemic circulation, and not directly within individual brain tumor cells. Therefore, nanoparticlebased slow sustained-drug release formulations of small molecule chemotherapy drugs that are larger than the 12 $\mathrm{nm}$ physiologic upper limit of pore size in the BBTB result in sub-therapeutic drug concentrations within individual brain tumor cells, since free drug is not released directly within individual brain tumor cells [70-72].

\section{Novel strategy to improve the effectiveness of systemic chemotherapy}

The novel strategy that I propose here to improve the effectiveness of systemic chemotherapy in the treatment of malignant brain tumors is based on my two recent observations $[59,73,74]$. The first observation being that spherical nanoparticles smaller than $12 \mathrm{~nm}$ in diameter, but not larger, can extravasate across the porous BBTB of malignant brain tumor microvasculature[73,74]. The second observation being that the subset of nanoparticles ranging between $7 \mathrm{~nm}$ and $10 \mathrm{~nm}$ in diameter are of sizes 
sufficiently smaller than the $12 \mathrm{~nm}$ physiologic upper limit of pore size within the BBTB and maintain peak blood concentrations for several hours, and therefore, can accumulate over time to effective concentrations within individual brain tumor cells[73,74]. Based on these two observations, spherical nanoparticles ranging between 7 $\mathrm{nm}$ and $10 \mathrm{~nm}$ in diameter can be used to deliver therapeutic concentrations of small molecule chemotherapy drugs across the BBTB and into individual malignant brain tumor cells. Since systemically administered nanoparticles within this 7 to $10 \mathrm{~nm}$ size range would not extravasate across the normal BBB of brain microvasculature [73-77] or across the endothelial barriers of most normal tissue microvasculature $[59,63,78,79]$, these nanoparticles would extravasate "selectively" across the porous BBTB of malignant brain tumor microvasculature.

We have recently demonstrated that an imageable nanoparticle bearing chemotherapy within the 7 to $10 \mathrm{~nm}$ size range at delivers therapeutic concentrations of small molecule chemotherapy across the BBTB into individual brain tumor cells. This prototype of an imageable nanoparticle bearing small molecule chemotherapy is a gadolinium (Gd)-diethyltriaminepentaacetic acid (DTPA) chelated generation 5 (G5) polyamidoamine (PAMAM) dendrimer with a proportion of the available terminal amines conjugated via $\mathrm{pH}$-sensitive covalent linkages to doxorubicin (Adriamycin; MW $0.580 \mathrm{kDa}$ ), a fluorescent small molecule chemotherapy drug that intercalates with DNA and inhibits the DNA replication process. The initial therapeutic efficacy of the Gd-G5-doxorubicin dendrimer has been tested in the orthotopic RG-2 rodent malignant glioma model. In this rodent glioma model we have found that one dose of the Gd-G5-doxorubicin dendrimer is significantly more effective than one dose of free doxorubicin at inhibiting the growth of RG-2 gliomas for approximately 24 hours.

\section{The physiologic upper limit of pore size in the BBTB of malignant brain tumor microvasculature}

Simple diffusion of nutrients and metabolites between tumor cells and pre-existent host tissue microvasculature is only sufficient to sustain solid tumor growth to a volume of 1 to $2 \mathrm{~mm}^{3}$ [80]. Additional tumor growth requires the formation of new microvasculature, a process that is mediated by vascular endothelial growth factor (VEGF)[81]. The new tumor microvasculature induced by VEGF is discontinuous due to the presence of anatomic defects within and between endothelial cells of the tumor barrier $[82,83]$. These anatomic defects in the tumor barrier can be several hundred nanometers wide [84-86]. For this reason, the endothelial barrier of malignant solid tumor microvasculature is more permeable to the transvascular passage of macromolecules than the endothelial barriers of normal tissue microvasculature including that of the kidney glomeruli[83,87]. Even though the anatomic defects within the endothelial barriers of malignant solid tumor microvasculature are relatively wide [84-86], we have found that in the physiologic state in vivo there is a fairly well-defined upper limit of pore size, which is approximately $12 \mathrm{~nm}$, independent of whether the location of the malignant solid tumor is within the brain and the central nervous system[73,74], or outside of it, in peripheral tissues[74].

Polyamidoamine (PAMAM) dendrimers functionalized with gadolinium (Gd)-diethyltriaminepentaacetic acid (DTPA), a small molecule MRI contrast agent, range in diameter between $1.5 \mathrm{~nm}$ (Gd-DTPA PAMAM dendrimer generation 1, Gd-G1) and 14 nm (Gd-DTPA PAMAM dendrimer generation 8, Gd-G8)[73,74]. Since each Gd-DTPA moiety carries a charge of -2 , conjugation of Gd-DTPA to a significant proportion of the terminal amine groups on PAMAM dendrimer exterior neutralizes the positively charged exterior of naked PAMAM dendrimers (Figure 1, panels A and B). The masses of Gd-G5 through Gd-G8 dendrimer particles are sufficient enough for particle visualization by annular dark-field scanning transmission electron microscopy (ADF STEM) $[73,74,88]$, and the sizes of Gd-G7 and Gd-G8 dendrimer particles are large enough for estimation of particle diameters, which are approximately $11 \mathrm{~nm}$ for Gd-G7 dendrimers and approximately $13 \mathrm{~nm}$ for Gd-G8 dendrimers (Figure 1, panel C)[73,74].

Particle transvascular extravasation across the BBTB and accumulation within the extravascular compartment of brain tumor tissue has been historically measured with quantitative autoradiography [89-91], which only provides information about particle accumulation once per specimen at post-mortem, or by intravital fluorescence microscopy[92], which requires that tumors be grown in dorsal window chambers and provides low-resolution real-time data. In more recent years, dynamic contrastenhanced MRI has been used to visualize the degree of particle transvascular extravasation across the ВВТВ $[59,73,93,94]$, since it is non-invasive and provides high-resolution real-time data. With dynamic contrastenhanced MRI it is possible to measure over time the degree of Gd-dendrimer extravasation across the BBTB and accumulation in the extravascular compartment of tumor tissue. The Gd-dendrimer concentration in tumor tissue can be estimated by the in vivo measurement of tumor tissue MRI signal at baseline $\left(T_{10}\right)$ and then again following the intravenous infusion of the Gd-dendrimer $\left(T_{1}\right)$, and the in vitro measurement of the molar relaxivity $\left(r_{1}\right)$ of the Gd-dendrimer, which is the proportionality constant for conversion of Gd signal to Gd concentration $[73,74,95]$. 

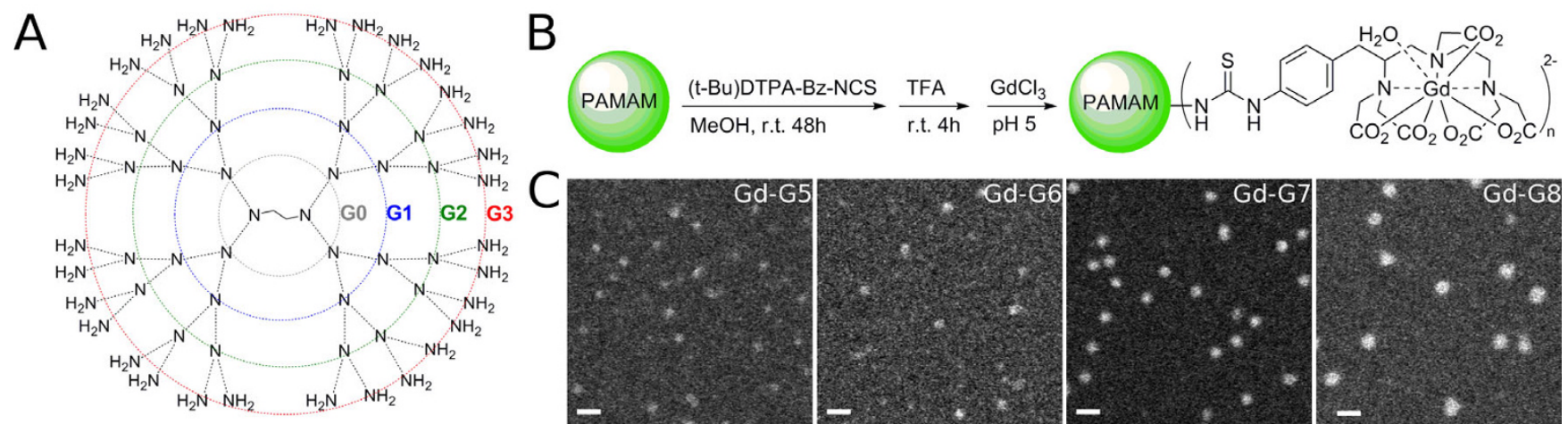

Figure I

Synthesis of gadolinium (Gd)-diethyltriaminepentaacetic acid (DTPA) conjugated polyamidoamine (PAMAM) dendrimers and images of higher generation (G) Gd-dendrimers with annular dark-field scanning transmission electron microscopy. A) Illustrations of naked PAMAM dendrimer generations from the ethylenediamine core (G0) to generation 3 (G3). The exterior of naked PAMAM dendrimers is positively charged due to the presence of terminal amine groups. The number of terminal amine groups doubles with each successive generation. B) Synthetic scheme for the production of GdDTPA conjugated PAMAM dendrimers. The conjugation of Gd-DTPA (charge -2) to the terminal amine groups neutralizes the positive charge on the dendrimer exterior. C) Annular dark-field scanning transmission electron microscopy images of Gd-G5, Gd-G6, Gd-G7, and Gd-G8 dendrimers adsorbed onto an ultrathin carbon support film. The average diameter of sixty Gd-G7 dendrimers is II $.0 \pm 0.7 \mathrm{~nm}$ and that of sixty Gd-G8 dendrimers is I $3.3 \pm 1.4 \mathrm{~nm}$ (mean \pm standard deviation). Scale bar $=20$ $\mathrm{nm}$. Adapted from reference[73].

We have determined that Gd-G1 through Gd-G7 dendrimer particles traverse the pores of the BBTB of RG-2 rodent malignant glioma microvasculature and enter the extravascular compartment of tumor tissue, but that the Gd-G8 dendrimer particles remain intravascular (Figure 2, panels A and B) $[73,74]$. Therefore, the physiologic upper limit of pore size within the BBTB of malignant brain tumor microvasculature is approximately $12 \mathrm{~nm}$, since Gd-G7 dendrimers, being approximately $11 \mathrm{~nm}$ in diameter, can extravasate across the BBTB, whereas Gd-G8 dendrimers, being approximately $13 \mathrm{~nm}$ in diameter, cannot[73,74]. On comparison of the physiologic upper limit of pore size in the BBTB of small RG-2 glioma microvasculature to that of the BBTB of large RG-2 glioma microvasculature, we have found that Gd-G1 through GdG6 dendrimers also readily traverse pores within the BBTB of small RG-2 glioma microvasculature (Figure 2, panel B)[73]. However, Gd-G7 dendrimers do not readily extravasate across the BBTB of small RG-2 glioma microvasculature (Figure 2, panel B)[73]. This finding is consistent with the likelihood that the physiologic upper limit of pore size in the ВBTB of the microvasculature of early, less mature and smaller malignant brain tumor colonies is 1 to 2 nanometers lower than that of the BBTB of the microvasculature of late, more mature and larger malignant brain tumors. Since most small molecule chemotherapy drugs are less than 1 to $2 \mathrm{~nm}$ in diameter, a slightly lower physiologic upper limit of pore size in the BBTB of the microvasculature of early, less mature and smaller malignant brain tumor colonies does not explain why small molecule chemotherapy drugs do not accumulate to effective concentrations within the extravascular compartment of early, less mature and smaller malignant brain tumor colonies, whether primary or metastatic.

\section{Significance of the luminal glycocalyx layer of the BBTB of malignant brain tumor microvasculature}

The well-defined physiologic upper limit of pore size in the BBTB of $12 \mathrm{~nm}$ would be attributable to the presence of a luminal glycocalyx layer overlaying the anatomic defects within the BBTB. Since the fibrous matrix of the glycocalyx overlaying endothelial barriers may be several hundred nanometers thick [96-100], it would be the "nanofilter" that serves as the main point of resistance to the transvascular passage of spherical particles larger than $12 \mathrm{~nm}$ in diameter across the BBTB. Therefore, in the physiologic state in vivo, the presence of the glycocalyx would render the underlying endothelial cells of the BBTB inaccessible to the transvascular passage of liposomes, viruses, bacteria, or cells, unless the glycocalyx was stretched, degraded, or disrupted in some manner [101107]. Furthermore, the glycocalyx layer would also be expected to offer considerable resistance to the transvascular passage of non-spherical particles with sizes at the cusp of the physiologic upper limit of pore size including monoclonal antibodies (immunoglobulin G, IgG), which have sizes of approximately $11 \mathrm{~nm}$ based on the calculation of antibody diffusion coefficients in viscous fluids[108]. The $12 \mathrm{~nm}$ physiologic upper limit of pore size 

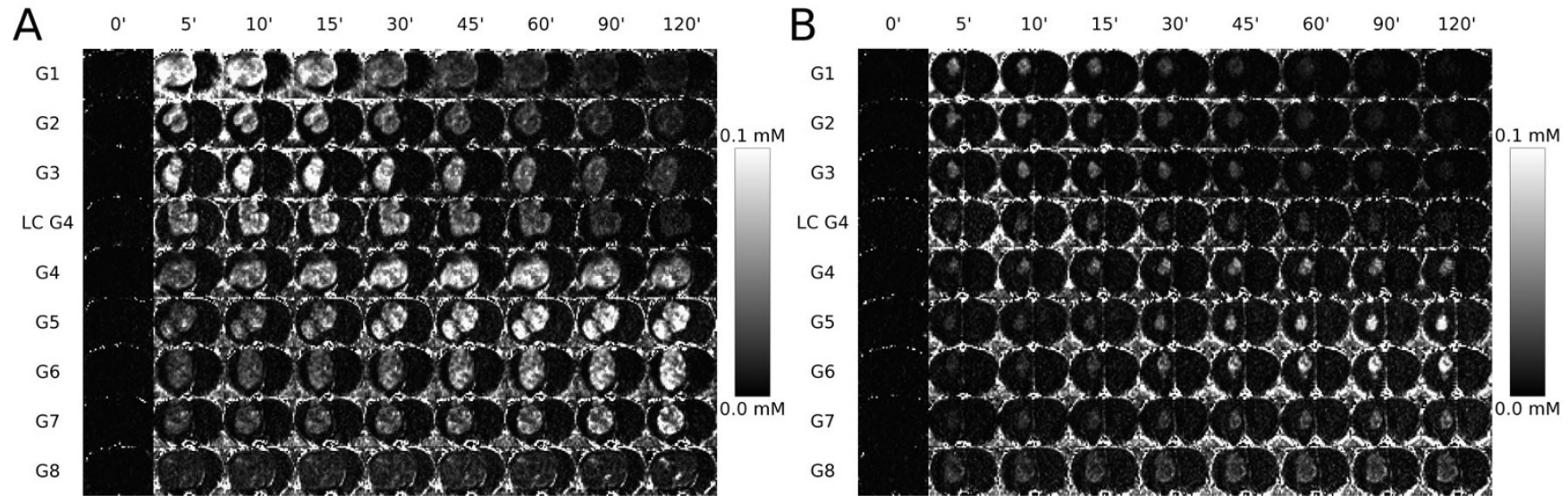

Figure 2

Dynamic contrast-enhanced MRI-based Gd concentration maps of $\mathbf{G d - d e n d r i m e r}$ distribution within large and small RG-2 rodent gliomas over time. A) Large RG-2 gliomas. Gd-GI thorough Gd-G7 dendrimers extravasate across the BBTB of the microvasculature of large RG-2 gliomas. After extravasating across the BBTB, Gd-GI through Gd-G4 dendrimers only remain temporarily within the extravascular compartment of tumor tissue, as these lower Gd-dendrimer generations maintain peak blood concentrations for only a few minutes. The Gd-G5 through Gd-G7 dendrimers accumulate over time within the extravascular compartment of tumor tissue, as these generations maintain peak blood concentrations for several hours. The Gd-G8 dendrimers remain intravascular, since Gd-G8 dendrimers are larger than the physiologic upper limit of pore size in the BBTB of large RG-2 gliomas. RG-2 glioma volumes (mm3): Gd-GI, I04; Gd-G2, 94; Gd-G3, 94; lowly conjugated (LC) Gd-G4, I62; Gd-G4, 200; Gd-G5, 230; Gd-G6, 20I; Gd-G7, I70; Gd-G8, 289. B) Small RG-2 gliomas. Gd-GI thorough Gd-G6 dendrimers extravasate across the BBTB of the microvasculature of small RG-2 gliomas. Since small RG-2 gliomas are less vascular than large RG-2 gliomas, there is a relative lack of accumulation of the lower Gd-dendrimer generations in the extravascular compartment of small RG-2 gliomas as compared to large RG-2 gliomas (panel A). This is especially evident in the case of Gd-GI dendrimers, which maintain peak blood concentrations for the shortest time period of all the Gd-dendrimer generations. Gd-G5 and Gd-G6 dendrimers accumulate over time within the extravascular compartment of even the small RG2 gliomas, since these generations maintain peak blood concentrations fro several hours and are smaller than the physiologic upper limit of pore size in the BBTB. Both Gd-G7 and Gd-G8 dendrimers remain intravascular in small RG-2 gliomas, since both Gd-G7 and Gd-G8 dendrimers are larger than the physiologic upper limit of pore size in the BBTB of small RG-2 gliomas. RG-2 glioma volumes (mm³): Gd-GI, 27; Gd-G2, 28; Gd-G3, 19; LC Gd-G4, 24; Gd-G4, I7; Gd-G5, I8; Gd-G6, 22; Gd-G7, 24; Gd-G8, 107. Respective Gd-dendrimer generations administered intravenously over I minute at a Gd dose of $0.09 \mathrm{mmol} \mathrm{Gd} /$ $\mathrm{kg}$ animal body weight. Scale ranges from $0 \mathrm{mM}$ [Gd] to $0.1 \mathrm{mM}$ [Gd]. Adapted from reference[73].

is the likely reason why monoclonal antibody-based systemic chemotherapy has not been effective at treating malignant solid tumors[109].

\section{Nanoparticle blood half-life and particle accumulation within individual brain tumor cells} With dynamic-contrast enhanced MRI we have characterized the relationship between Gd-dendrimer blood halflife and transvascular extravasation across the BBTB of RG2 rodent malignant gliomas. Based on our findings, it is evident that spherical nanoparticles ranging between 7 $\mathrm{nm}$ an $10 \mathrm{~nm}$ in diameter maintain peak blood concentrations for several hours and are sufficiently smaller than the $12 \mathrm{~nm}$ physiologic upper limit of pore size in the BBTB to accumulate to effective concentrations within individual brain tumor cells[73,74]. For spherical particles that are smaller than $6 \mathrm{~nm}$ in diameter, the distribution of particles within the extravascular compartment of tumor tissue becomes more focal as particle size increases, since these particles maintain peak blood concentrations for only minutes[73]. However, for spherical particles that range between $7 \mathrm{~nm}$ and $10 \mathrm{~nm}$ in diameter, the distribution of particles within the extravascular compartment of tumor tissue is widespread, irrespective of particle size, since these particles maintain peak blood concentrations for several hours $[73,74]$.

Spherical particles smaller than $6 \mathrm{~nm}$ in diameter (MW less than 40 to $50 \mathrm{kDa})[88,110-112]$, which is the size range of Gd-G1 through Gd-G4 dendrimers, possess relatively short blood half-lives[73], and therefore, maintain peak blood concentrations for only minutes (Figure 3) [73], as these particles are small enough to be efficiently filtered by the kidney glomeruli[113]. As such, particles smaller than $6 \mathrm{~nm}$ only remain temporarily within the extravascular compartment of tumor tissue (Figure 2, rows 1 through 5)[73], which would not be sufficient time for particles to accumulate to therapeutic concentrations 


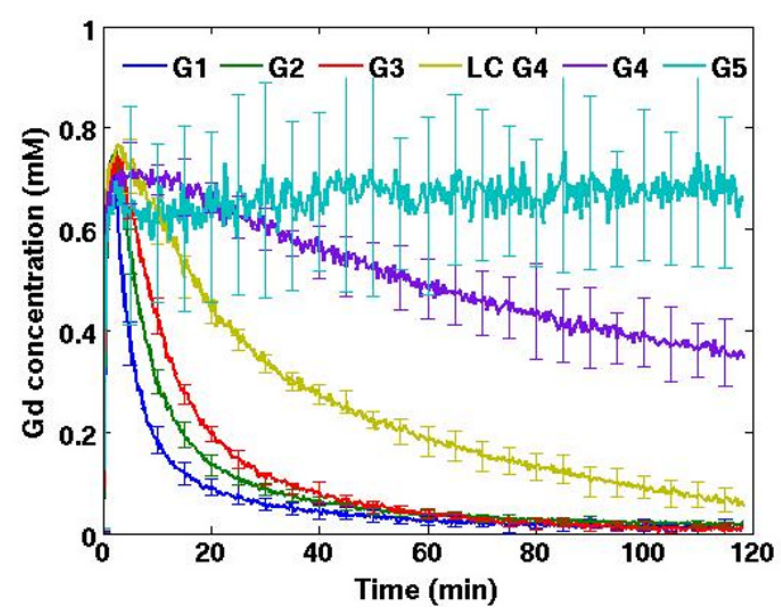

Figure 3

Steady-state blood concentrations of successively higher generation $\mathbf{G d}$-dendrimers over time in rodents. Gd-GI dendrimers (MW $6 \mathrm{kDa}$ ), Gd-G2 dendrimers (MW II kDa), Gd-G3 dendrimers (MW I9 kDa), lowly conjugated (LC) Gd-G4 dendrimers (MW $25 \mathrm{kDa}$ ), and standard Gd-G4 dendrimers (MW $40 \mathrm{kDa}$ ) maintain peak blood concentrations for only a few minutes. Gd-G5 dendrimers (MW $80 \mathrm{kDa}$ ) maintain peak blood concentrations for over 2 hours. Gd-G6 dendrimers (MW I30 kDa), Gd-G7 dendrimers (MW $330 \mathrm{kDa}$ ), and Gd-G8 dendrimers (MW $597 \mathrm{kDa}$ ) also maintain peak blood concentrations for over 2 hours similar to those of Gd-G5 dendrimers (concentration profiles not shown for purposes of figure clarity). Respective Gd-dendrimer generations administered intravenously over I minute at a Gd dose of $0.09 \mathrm{mmol} \mathrm{Gd} / \mathrm{kg}$ animal body weight. Blood concentrations of Gd-dendrimers over time measured in the superior sagittal sinus. Gd-GI $(n=4)$, Gd$\mathrm{G} 2(\mathrm{n}=6), \mathrm{Gd}-\mathrm{G} 3(\mathrm{n}=6)$ ), lowly conjugated (LC) Gd-G4 ( $=4), G d-G 4(n=6), G d-G 5(n=6), G d-G 6(n=5), G d-G 7$ $(n=5)$, and $G d-G 8(n=6)$. Error bars represent standard deviations. Adapted from reference[73].

within individual brain tumor cells. The blood half-life of small molecule chemotherapy drugs would be even shorter than that of the smallest Gd-dendrimer, the GdG1 dendrimer (Figure 2, row 1)[73]. Therefore, the short blood half-life of small molecule chemotherapy drugs would be the primary reason why these small drugs do not accumulate to therapeutic concentrations within individual brain tumor cells after extravasating across the porous BBTB of malignant brain tumor microvasculature.

Spherical particles greater than $7 \mathrm{~nm}$ in diameter (MW greater than 70 to $80 \mathrm{kDa}$ )[88,110-112], which is the size range of Gd-G5 through Gd-G8 dendrimers, possess relatively long particle blood half-lives[74], and therefore, maintain peak blood concentrations for several hours (Figure 3)[73,74], as these particles are too large to be filtered by the kidney glomeruli. Particles ranging between 7 $\mathrm{nm}$ and $10 \mathrm{~nm}$ in diameter, those being Gd-G5 and Gd-
G6 dendrimers, slowly accumulate over 2 hours within the extravascular compartment of even small RG-2 malignant gliomas (Figure 2, rows 6 and 7)[73]. Due to the prolonged residence time of particles within the extravascular compartment of tumor tissue, there is significant endocytosis of particles into individual RG-2 glioma cells, which is evident on fluorescence microscopy of tumor tissue harvested 2 hours following the intravenous administration of rhodamine B dye conjugated Gd-G5 dendrimers (Figure 4, panel D)[73]. This finding indicates that spherical nanoparticles ranging between $7 \mathrm{~nm}$ and $10 \mathrm{~nm}$ in diameter can be used to deliver therapeutic concentrations of small molecule chemotherapy drugs across the BBTB and into individual malignant glioma cells. Furthermore, with spherical particles in the 7 to $10 \mathrm{~nm}$ size range, it would be possible to deliver therapeutic concentrations of small molecule chemotherapy drugs across the BBTB of the microvasculature of early, less mature and smaller brain tumor colonies (Figure 2, panel B, rows 6 and 7), even though these smaller tumors are less vascular than late, more mature and larger malignant brain tumors[59,73,90,91,114,115].

\section{Issue of positive charge on the nanoparticle exterior}

Small molecules and peptides with significant focal positive charges [116,117] can disrupt the luminal glycocalyx layer, which is a polysaccharide matrix bearing an overall negative charge[96]. When positively charged small molecules are attached to the exterior of nanoparticles with long blood half-lives, the prolonged exposure of the cationic particle surface to the glycocalyx can result in its significant disruption[116,118]. Prior to our recent studies on the physiologic upper limit of the pore size within the BBTB of malignant brain tumors and the blood-tumor barrier (BTB) of malignant peripheral tumors[73,74], the pore size within the BBTB and ВТВ had been probed by intravital fluorescence microscopy 24 hours following the intravenous infusion of cationic liposomes and microspheres labeled on the exterior with rhodamine B dye $[116,119,120]$. Since, in these prior studies, the intravital fluorescence microscopy of particle extravasation across the BBTB and BTB was performed 24 hours following the intravenous infusion of cationic nanoparticles $[119,120]$, it is to be expected that the measured physiologic pore sizes with this approach would approximate the sizes of anatomic defects underlying the glycocalyx[85], as 24 hours would be sufficient time for cationic nanoparticles to completely disrupt the glycocalyx and expose the underlying anatomic defects within the respective tumor barriers.

The positive charge on exterior of the naked PAMAM dendrimer generations is neutralized by the conjugation of Gd-DTPA (charge -2) to a significant proportion of the terminal amines. Therefore, intravenously administered Gd- 
DTPA conjugated dendrimer generations do not disrupt the glycocalyx overlaying the already porous BBTB and the normally non-porous BBB. However, when rhodamine $\mathrm{B}$ dye is conjugated to Gd-dendrimer terminal amines this positively charged molecule protrudes above the negatively charged Gd-DTPA moieties and re-introduces positive charge to the particle exterior, which results in positive charge-induced disruption of the glycocalyx of the already porous BBTB and the normally non-porous $\mathrm{BBB}$. The disruption of the glycocalyx overlaying the already porous BBTB results in enhanced extravasation of rhodamine $\mathrm{B}$ conjugated Gd-G5 dendrimers across the BBTB and in some minimal extravasation of rhodamine $B$ conjugated Gd-G8 dendrimers across the BBTB, which is evident in vivo on dynamic contrast-enhanced MRI 5 to 10 minutes following the intravenous infusion of the respective rhodamine $\mathrm{B}$ conjugated Gd-dendrimer generations(Figure 4, panel C)[73]. It is also evident ex vivo on fluorescence microscopy of RG-2 glioma specimens harvested at 2 hours following intravenous infusion of the respective rhodamine $\mathrm{B}$ conjugated $\mathrm{Gd}$-dendrimer generations (Figure 4, panels D and E)[73]. This finding is consistent with the greater exposure of underlying preexistent anatomic defects in the BBTB and a slight increase in the physiologic upper limit of pore size in the BBTB due to positive charge-induced toxicity to the glycocalyx.

The disruption of the glycocalyx overlaying the normally non-porous BBB results in some non-selective minimal extravasation of both rhodamine B conjugated Gd-G5 and rhodamine $\mathrm{B}$ conjugated Gd-G8 dendrimers across the $\mathrm{BBB}$, which is evident in vivo on dynamic contrastenhanced MRI 30 to 45 minutes following the intravenous infusion of the respective rhodamine $\mathrm{B}$ conjugated Gd-dendrimer generations[73]. It is also evident ex vivo on fluorescence microscopy of the normal brain tissue surrounding RG-2 glioma tumor tissue (Figure 4, panels D and E)[73]. This finding is consistent with the formation of new anatomic defects within and between endothelial cells of the BBB following disruption of the overlaying glycocalyx. On the basis of our recent findings[73,74], in the context of what has been previously reported[106,107,121], it is evident that the presence of positive charge on the nanoparticle exterior enhances the transvascular extravasation of particles across pathologic tumor barriers, and also across normal endothelial barriers, by positive charge-induced toxicity to the luminal glycocalyx layer.

\section{The prototype of an imageable nanoparticle bearing chemotherapy within the 7 to $10 \mathrm{~nm}$ size range: The Gd-G5-doxorubicin dendrimer}

Based on our finding that spherical nanoparticles ranging between $7 \mathrm{~nm}$ and $10 \mathrm{~nm}$ in diameter effectively traverse pores within the BBTB and accumulate to high concentra- tions within individual brain tumor cells, an imageable nanoparticle bearing chemotherapy within the 7 to $10 \mathrm{~nm}$ size range, the Gd-G5-doxorubicin dendrimer, has been developed (Figure 5, panel A). The Gd-G5-doxorubicin dendrimer has been visualized in vitro with annular darkfield scanning electron microscopy (Figure 5, panel B). Gd-DTPA was conjugated to approximately $50 \%$ of the terminal amines and doxorubicin to approximately $8 \%$ of the terminal amines of a G5 PAMAM dendrimer (Table 1), which yielded the optimal ratio of contrast agent-to-drug for dynamic contrast-enhanced MRI and systemic chemotherapy, respectively.

The doxorubicin was conjugated to the Gd-G5 dendrimer terminal amines via a $\mathrm{pH}$-sensitive hydrazone bond that is stable at the physiologic $\mathrm{pH}$ of 7.4, and labile at the acidic $\mathrm{pH}$ of 5.5 in lysosomal compartments [122-125]. The functionality of the $\mathrm{pH}$-sensitive hydrazone bond was verified in vitro with fluorescence microscopy, which showed that there is accumulation of free doxorubicin in RG-2 glioma cell nuclei following the incubation of glioma cells for 4 hours in media containing Gd-G5-doxorubicin dendrimers (Figure 5, panel $\mathrm{C}$ ). The relative stability of the hydrazone bond at physiologic $\mathrm{pH}$ would limit doxorubicin release in the systemic blood circulation and minimize any systemic toxicity associated with free drug release in the bloodstream, prior to particle extravasation across the BBTB. It would be expected that there would be limited free drug release within the extravascular extracellular compartment of tumor tissue after particle extravasation across the BBTB, since the extravascular extracellular compartment is significantly less acidotic than the intracellular lysosomal compartments of cells[124,126]. Furthermore, there would be rapid doxorubicin release following particle endocytosis into tumor cell lysosomal compartments, which would enable the free doxorubicin to traverse the nuclear pores and interact with the DNA. Most small molecule chemotherapy drugs act within the cell nucleus, which necessitates that free drug be released into the tumor cell cytoplasm, which would not be possible to accomplish with spherical nanoparticles larger than Gd-G2 dendrimers, as particles of sizes larger than Gd-G2 dendrimers do not appear to effectively traverse nuclear pores (Figure 4, panel B)[73].

The cytotoxicity of the Gd-G5-doxorubicin dendrimer was verified in vitro with RG-2 glioma cell survival measured by the MTT (3-(4,5-dimethylthiazol-2-yl)-2,5-diphenyltetrazolium bromide) assay[127]. The Gd-G5-doxorubicin dendrimer was intravenously bolused over 2 minutes to orthotopic RG-2 glioma bearing rodents at a dose of $8 \mathrm{mg} / \mathrm{kg}$ with respect to doxorubicin. On dynamic contrast-enhanced MRI over 1 hour, it was evident that the Gd-G5-doxorubicin dendrimer extravasates across the BBTB and accumulates within the extravascular compart- 

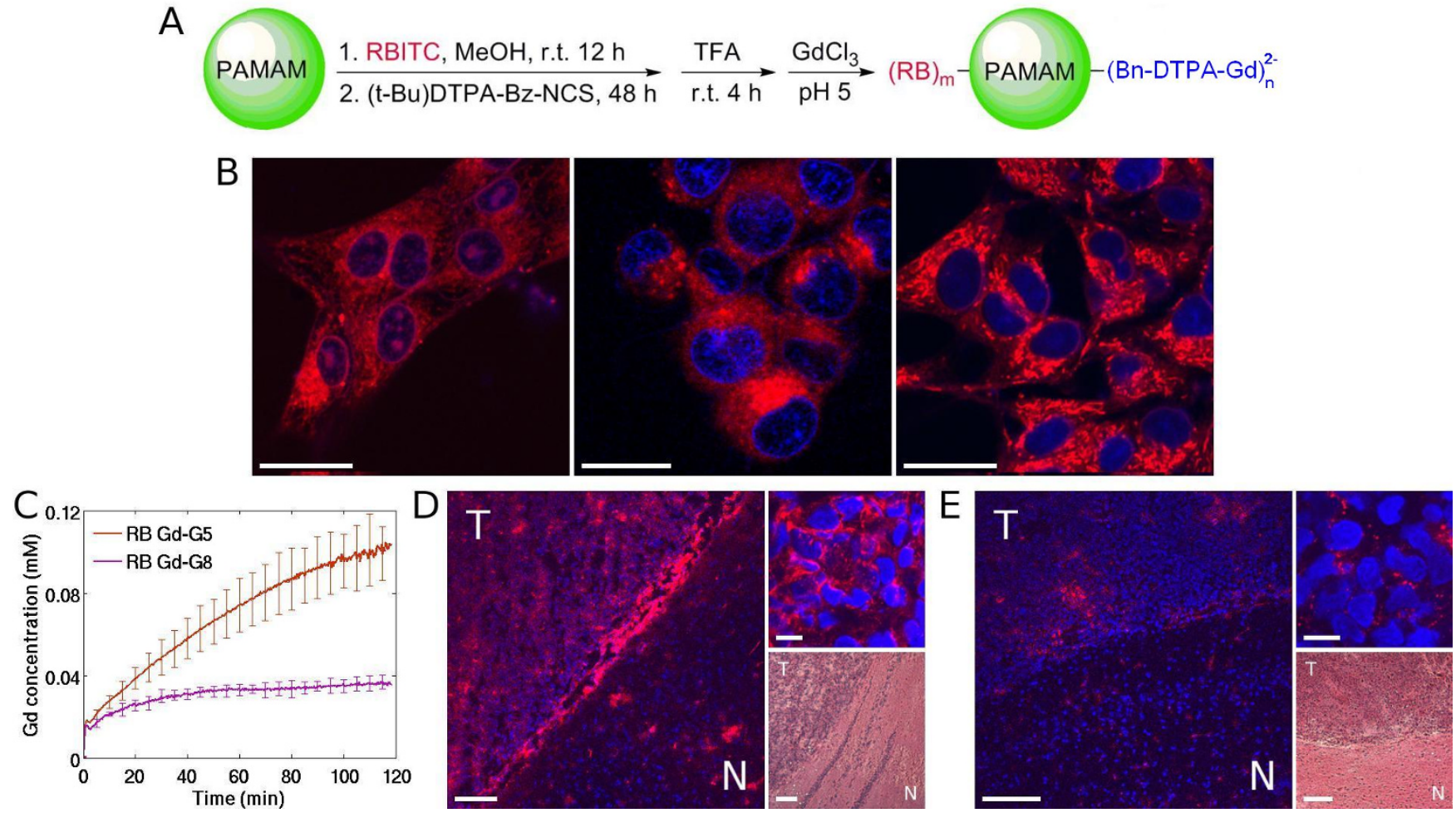

Figure 4

Synthesis of rhodamine B dye (RB) conjugated Gd-dendrimers and fluorescence microscopy of rhodamine B conjugated Gd-dendrimer uptake in cultured RG-2 glioma cells versus in RG-2 glioma cells of harvested RG-2 glioma tumor specimens. A) Synthetic scheme for production of rhodamine B dye conjugated Gd-dendrimers. Rhodamine $\mathrm{B}$ and DTPA are conjugated to the naked dendrimer terminal amines via stable covalent bonds. In functionalized dendrimers, approximately $35 \%$ of the terminal amines are occupied by Gd-DTPA, and approximately $7 \%$ of the terminal amines are occupied by rhodamine B. B) In vitro fluorescence microscopy of cultured RG-2 glioma cells incubated for 4 hours in media containing either rhodamine B conjugated Gd-G2 dendrimers (left), rhodamine B conjugated Gd-G5 dendrimers (middle), or rhodamine $B$ conjugated Gd-G8 dendrimers (right) at a concentration of $7.2 \mu M$ with respect to rhodamine $B$. Scale bars $=20$ $\mu \mathrm{m}$. Rhodamine B conjugated Gd-G2 dendrimers enter RG-2 glioma cells, and in some cases, the cell nuclei (left). Rhodamine B conjugated Gd-G5 dendrimers (middle) and rhodamine B conjugated Gd-G8 dendrimers (right) enter the cytoplasm of RG-2 glioma cells, but do not localize within the nuclei. C) Dynamic contrast-enhanced MRI-based Gd concentration curves of RG-2 glioma tumor tissue over time following the intravenous bolus of $0.06 \mathrm{mmol} \mathrm{Gd} / \mathrm{kg}$ of rhodamine B conjugated Gd-G5 dendrimers $(n=6)$ and rhodamine $B$ conjugated $G d-G 8$ dendrimers $(n=2)$. There is substantial extravasation of rhodamine $B$ conjugated Gd-G5 dendrimers across the BBTB, which is more pronounced than that of Gd-G5 dendrimers across the BBTB. There is also some extravasation of rhodamine B conjugated Gd-G8 dendrimers across the BBTB, which is not the case for Gd-G8 dendrimers. D) Ex vivo low power fluorescence microscopy of RG-2 glioma tumor and surrounding brain tissue harvested at 2 hours following the intravenous bolus of rhodamine B conjugated Gd-G5 dendrimers. There is substantial accumulation of rhodamine B conjugated Gd-G5 dendrimers within tumor tissue, and some in surrounding normal brain tissue (left, $T$ $=$ tumor, $\mathrm{N}=$ normal, scale bar $=100 \mu \mathrm{m})$. High power image of RG-glioma tumor shows subcellular localization of rhodamine B conjugated Gd-G5 dendrimers within individual RG-2 malignant glioma cells (upper right, scale bar $=20 \mu \mathrm{m}$ ). H\&E stain of tumor and surrounding brain (lower right, scale bar $=100 \mu \mathrm{m}$ ). Tumor volume is $3 \mathrm{I} \mathrm{mm}^{3}$. E) Ex vivo low power fluorescence microscopy of RG-2 glioma tumor and surrounding brain tissue harvested at 2 hours following the intravenous bolus of rhodamine B conjugated Gd-G8 dendrimers. There is some minimal accumulation of rhodamine B conjugated Gd-G8 dendrimers within brain tumor tissue (left, $T=$ tumor, $N=$ normal, scale bar $=100 \mu \mathrm{m}$ ). High power confirms there is some minimal subcellular localization of rhodamine B conjugated Gd-G8 dendrimers within individual RG-2 glioma cells (upper right, scale bar = $20 \mu \mathrm{m})$. H\&E stain of tumor and surrounding brain (lower right, scale bar $=100 \mu \mathrm{m}$ ). Tumor volume is $30 \mathrm{~mm}^{3}$. Rhodamine B conjugated Gd-G5 dendrimers and rhodamine B conjugated Gd-G8 dendrimers administered intravenously over I minute at a $\mathrm{Gd}$ dose of $0.06 \mathrm{mmol} \mathrm{Gd} / \mathrm{kg}$ animal body weight. Adapted from reference[73]. 

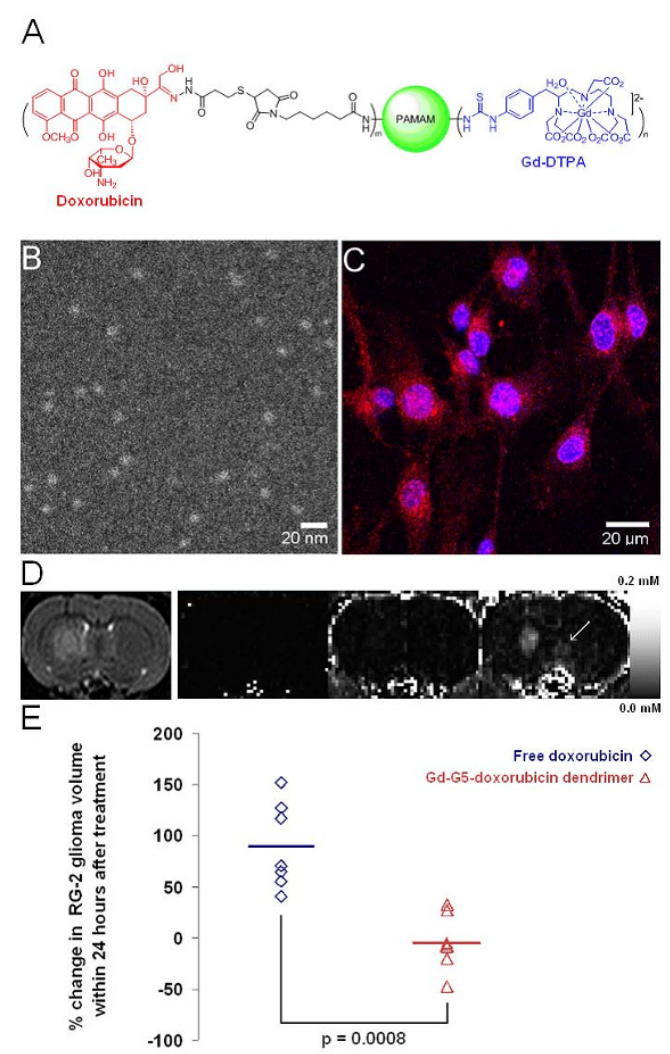

\section{Figure 5}

The prototype of an imageable nanoparticle bearing chemotherapy within the 7 to $10 \mathrm{~nm}$ size range: The $\mathbf{G d}$ G5-doxorubicin dendrimer. A) An illustration of the Gd-G5-doxorubicin dendrimer. Doxorubicin is conjugated to the dendrimer terminal amines by a $\mathrm{pH}$-sensitive hydrazone bond, which facilitates the rapid release of doxorubicin following particle endocytosis into brain tumor cell lysosomal compartments. B) Annular dark-field scanning transmission electron microscopy image of Gd-G5-doxorubicin dendrimers. C) In vitro fluorescence microscopy of cultured RG-2 glioma cells incubated for 4 hours in media containing Gd-G5-doxorubicin dendrimers at a $600 \mathrm{nM}$ concentration. The red fluorescence in the cytoplasm represents Gd-G5-doxorubicin dendrimers within the cytoplasm of RG-2 glioma cells. The red fluorescence within the RG-2 cell nuclei represents free doxorubicin that has been released from the Gd-G5-doxorubicn dendrimers following cleavage of the hydrazone bond, since particles larger than Gd-G2 dendrimers are too large to pass through the nuclear pores. D) $T_{2}-$ weighted anatomic scan image and $T_{1}$-weighted dynamic contrast-enhanced MRI scan Gd concentration map images at various time points up to 60 minutes following Gd-G5-doxorubicn dendrimer infusion. The Gd-G5-doxorubicin dendrimer was administered intravenously over 2 minutes at a Gd dose of $0.09 \mathrm{mmol} \mathrm{Gd} / \mathrm{kg}$, which is equivalent to a doxorubicin dose of $8 \mathrm{mg} / \mathrm{kg}$. The $T_{2}$-weighted anatomic scan image shows the location of the RG-2 glioma in the right caudate of rat brain, which has a tumor volume of $16 \mathrm{~mm}^{3}$. The first $T_{1}$-weighted dynamic contrast-enhanced MRI scan image displays the lack of contrast enhancement prior to Gd-G5 doxorubicin dendrimer infusion. The second $T_{1}$-weighted dynamic contrast-enhanced MRI scan image confirms contrast enhancement in the vasculature immediately after Gd-G5-doxorubicin dendrimer infusion. The third $T_{1}$-weighted dynamic contrast-enhanced MRI scan image shows that at 60 minutes following the Gd-G5-doxorubicin dendrimer infusion there is significant Gd-G5-doxorubicin accumulation within the RG-2 glioma tumor extravascular extracellular space, which confirms that the Gd-G5-doxorubicin dendrimer has extravasated slowly across the BBTB over timer due to its long blood half-life. The white arrow highlights that there is positive contrast enhancement of normal brain tissue, which indicates that there is extravasation of the Gd-G5-doxorubicin dendrimer across the normal BBB. E) Percent change in RG-2 malignant glioma volume within 24 hours. One group of orthotopic RG-2 glioma bearing animals received one intravenous $8 \mathrm{mg} / \mathrm{kg}$ dose of Gd-G5-doxorubicin dendrimer with respect to doxorubicin $(n=7)$, and the other group of glioma bearing animals received one $8 \mathrm{mg} / \mathrm{kg}$ dose of free doxorubicin $(\mathrm{n}=7)$. Pre-treatment whole RG-2 glioma tumor volumes calculated based on initial $T_{2}-$ weighted anatomic scans acquired immediately prior to agent administration, and post-treatment whole RG-2 glioma tumor volumes calculated based on repeat $T_{2}$-weighted anatomic scans acquired within $22 \pm 2$ hours for the Gd-G5-doxorubicin group and $24 \pm \mathrm{I}$ hour for the free doxorubicin group. One dose of the Gd-G5-doxorubicin dendrimer is significantly more effective than one dose of free doxorubicin at inhibiting the growth of orthotopic RG-2 malignant gliomas for approximately 24 hours. Student's two-tailed paired t-test $p$ value $<0.0008$. 
Table I: Properties of the Gd-G5-doxorubicin dendrimer

\begin{tabular}{|c|c|c|c|c|c|c|}
\hline $\begin{array}{l}\text { PAMAM } \\
\text { dendrimer } \\
\text { generation } \\
\text { (G) }\end{array}$ & Terminal amines (\#) & $\begin{array}{c}\text { Naked } \\
\text { dendrimer } \\
\text { molecular weight } \\
(\mathrm{kDa})\end{array}$ & $\begin{array}{l}\text { Gd-G5-doxorubicin } \\
\text { dendrimer molecular } \\
\text { weight }(\mathrm{kDa})\end{array}$ & $\begin{array}{c}\text { Gd-DTPA } \\
\text { conjugation (\%) }\end{array}$ & $\begin{array}{c}\text { Doxorubicin } \\
\text { conjugation (\%) }\end{array}$ & $\begin{array}{c}\text { Molar relaxivity } \\
\left(\mathrm{mM}^{-1} \mathrm{~s}^{-1}\right)\end{array}$ \\
\hline G5 & 128 & $29 \#$ & $85 \ddagger$ & 48.1 & 7.8 & $10.1 \&$ \\
\hline
\end{tabular}

\# molecular weight of naked PAMAM dendrimer obtained from Dendritech, Inc.

łmolecular weight measured by MALDI-TOF mass spectrometry

\&molar relaxivity of Gd-DTPA measured to be $4.1 \mathrm{mM}^{-1} \mathrm{~s}^{-1}$

ment of brain tumor tissue over time (Figure 5, panel D). There was, however, also some transvascular extravasation of the Gd-G5-doxorubicin dendrimer across the normal $\mathrm{BBB}$ and non-selective accumulation of Gd-G5-doxorubicin dendrimer in normal brain tissue (Figure 5, panel D arrow), which would be attributable to the re-introduction of focal positive charge to the Gd-G5 dendrimer exterior due to the attachment of doxorubicin, which is a cationic drug[128]. Despite this drawback, one $8 \mathrm{mg} / \mathrm{kg}$ dose of Gd-G5-doxorubicin dendrimer with respect to doxorubicin was found to be significantly more effective than one $8 \mathrm{mg} / \mathrm{kg}$ dose of free doxorubicin at inhibiting the growth of orthotopic RG-2 malignant gliomas for approximately 24 hours (Figure 5, panel E). The shortterm efficacy of this approach stems from the accumulation of small molecule chemotherapy to therapeutic concentrations directly within individual brain tumor cells. The long-term efficacy of this approach will need to be evaluated in various animal malignant glioma models[129,130], prior to clinical translation.

Therapeutic implications and future perspective The Gd-G5-doxorubicin dendrimer, being a nanoparticle bearing chemotherapy within the $7 \mathrm{~nm}$ to $10 \mathrm{~nm}$ size range, delivers therapeutic concentrations of doxorubicin across the porous BBTB of malignant brain tumors into individual tumor cells. Doxorubicin attachment to the Gd-G5-doxorubicin dendrimer via $\mathrm{pH}$-sensitive hydrazone bonds facilitates rapid doxorubicin release within the brain tumor cell lysosomal compartments and the accumulation of released doxorubicin within tumor cell nuclei. The short-term efficacy of the Gd-G5-doxorubicin dendrimer in regressing RG-2 malignant gliomas stems from the effective transvascular delivery of doxorubicin across the BBTB into individual brain tumor cells. The attachment of doxorubicin to the Gd-G5 dendrimer exterior, however, re-introduces positive charge to Gd-G5dendrimer exterior, since the positively charged doxorubicin molecules protrude above the negatively charged Gd-DTPA molecules. The presence of positive charge on the Gd-G5-doxorubicin dendrimer exterior is toxic to the luminal glycocalyx layer and results in non-selective accumulation of the Gd-G5-doxorubicin dendrimer in normal brain tissue. Therefore, in the future, cationic small molecule chemotherapy drugs will need to be conjugated by hydrazone bonds closer to the particle interior, which would minimize the re-introduction of positive charge on the particle exterior. Furthermore, in the future, it may also be advantageous to use naked half generation PAMAM dendrimers (i.e. G5.5) as substrates for conjugation of cationic molecules, since these PAMAM dendrimer generations are anionic. Other types of biocompatible dendrimers, for example, those that are amino acid-based, would also be appropriate substrates for functionalization, provided there is no net positive charge on the functionalized particle surface.

Boron neutron capture therapy (BNCT)[131] has been relatively ineffective in the treatment of malignant brain tumors since it has not been possible to deliver high concentrations of ${ }^{10}$ boron $\left({ }^{10} \mathrm{~B}\right)$ into individual brain tumor cells. Local chemotherapy delivery methodologies such as convection-enhanced delivery (CED)[132,133] only deliver high concentrations of ${ }^{10} \mathrm{~B}$ within a few millimeters of the delivery site[134]. Intravenously administered imageable dendrimers within the $7 \mathrm{~nm}$ to $10 \mathrm{~nm}$ size range bearing polyhedral borane cages[135] could be used to deliver therapeutic concentrations of ${ }^{10} \mathrm{~B}$ to individual brain tumor cells. This is has not been possible to accomplish with: (1) the boronated G4 dendrimer-epidermal growth factor (BD-EGF) particle, as this particle has a molecular weight of approximately $35 \mathrm{kDa}[136]$, which would be consistent with a short blood half-life, and (2) the boronated monoclonal antibody[137], as the size of this antibody is close to the $12 \mathrm{~nm}$ physiological upper limit of pore size and the particle shape is nonspherical[108]. Spherical nanoparticles within the $7 \mathrm{~nm}$ to $10 \mathrm{~nm}$ size range bearing polyhedral borane cages would be able to deliver effective concentrations of ${ }^{10} \mathrm{~B}$ to individual brain tumor cells.

The premise underlying the future, successful, clinical translation of the proposed strategy is that the BBTB of malignant brain tumor microvasculature remain somewhat porous, which will necessitate that corticosteroid and VEGF inhibitor treatments be held to a minimum 
prior to and during the application of the proposed strategy, as it is known that these treatments significantly decrease the porosity of the BBTB. In summary, spherical nanoparticles ranging between $7 \mathrm{~nm}$ and $10 \mathrm{~nm}$ in diameter maintain peak blood concentrations for several hours and are sufficiently smaller than the $12 \mathrm{~nm}$ physiologic upper limit of pore size in the BBTB to accumulate to therapeutic concentrations within individual brain tumor cells. Therefore, nanoparticles bearing chemotherapy that are within this 7 to $10 \mathrm{~nm}$ size range can be used to deliver therapeutic concentrations of small molecule chemotherapy drugs across the BBTB into individual brain tumor cells.

\section{Competing interests}

The author declares that they have no competing interests.

\section{Authors' contributions}

HS conceptualized the work and wrote the manuscript.

\section{Acknowledgements}

This study was funded by the National Institute of Biomedical Imaging and Bioengineering, and the Clinical Center Radiology and Imaging Sciences Program. The synthesis and preliminary characterization of the functionalized dendrimers was performed by the Imaging Probe Development Center of the National Heart, Lung, and Blood Institute. The in vitro characterization of the functionalized dendrimers was performed by the Laboratory of Cell Biology of the National Cancer Institute.

\section{References}

I. Louis DN, Ohgaki H, Wiestler OD, Cavenee WK, Burger PC, Jouvet A, Scheithauer BW, Kleihues P: The 2007 WHO classification of tumours of the central nervous system. Acta Neuropathologica 2007, I I 4:97.

2. Barnholtz-Sloan JS, Sloan AE, Davis FG, Vigneau FD, Lai P, Sawaya RE: Incidence proportions of brain metastases in patients diagnosed (1973 to 200I) in the Metropolitan Detroit Cancer Surveillance System. Journal of Clinical Oncology 2004, 22:2865.

3. Schouten LJ, Rutten J, Huveneers HAM, Twijnstra A: Incidence of brain metastases in a cohort of patients with carcinoma of the breast, colon, kidney, and lung and melanoma. Cancer 2002, 94:2698.

4. Brown M, Schrot R, Bauer K, LeTendre D: Incidence of first primary central nervous system tumors in California, 20012005. Journal of Neuro-Oncology 2009: I.

5. Wohrer A, Waldhor T, Heinzl H, Hackl M, Feichtinger J, GruberMosenbacher U, Kiefer A, Maier H, Motz R, Reiner-Concin A, Richling B, Idriceanu C, Scarpatetti M, Sedivy R, Bankl HC, Stiglbauer W, Preusser M, Rossler K, Hainfellner JA: The Austrian Brain Tumour Registry: a cooperative way to establish a population-based brain tumour registry. Journal of Neuro-Oncology 2009:I.

6. Posner JB, Chernik NL: Intracranial metastases from systemic cancer. Advances in neurology 1978, 19:579.

7. Brem SS, Bierman PJ, Black P, Brem H, Chamberlain MC, Chiocca EA, DeAngelis LM, Fenstermaker RA, Friedman A, Gilbert MR, Glass ], Grossman SA, Heimberger AB, Junck L, Linette GP, Loeffler JJ, Maor MH, Moots P, Mrugala M, Nabors LB, Newton HB, Olivi A, Portnow J, Prados M, Raizer JJ, Shrieve DC, Sills AK Jr: Central nervous system cancers: Clinical Practice Guidelines in Oncology. JNCCN Journal of the National Comprehensive Cancer Network 2008, 6:456.

8. Stewart LA: Chemotherapy in adult high-grade glioma: A systematic review and meta-analysis of individual patient data from I 2 randomised trials. Lancet 2002, 359: I0 I I.
9. Ewend MG, Morris DE, Carey LA, Ladha AM, Brem S: Guidelines for the initial management of metastatic brain tumors: Role of surgery, radiosurgery, and radiation therapy. JNCCN Journal of the National Comprehensive Cancer Network 2008, 6:505.

10. Ranjan T, Abrey LE: Current Management of Metastatic Brain Disease. Neurotherapeutics 2009, 6:598.

II. Stafinski T, Jhangri GS, Yan E, Menon D: Effectiveness of stereotactic radiosurgery alone or in combination with whole brain radiotherapy compared to conventional surgery and/or whole brain radiotherapy for the treatment of one or more brain metastases: A systematic review and meta-analysis. Cancer Treatment Reviews 2006, 32:203.

12. Lutterbach J, Bartelt $S$, Ostertag $C$ : Long-term survival in patients with brain metastases. Journal of Cancer Research and Clinical Oncology 2002, I 28:4I7.

13. Nussbaum ES, Djalilian HR, Cho KH, Hall WA: Brain metastases: Histology, multiplicity, surgery, and survival. Cancer 1996, 78: $\mid 781$.

14. Laws ER, Parney IF, Huang W, Anderson F, Morris AM, Asher A, Lillehei KO, Bernstein M, Brem H, Sloan A, Berger MS, Chang S: Survival following surgery and prognostic factors for recently diagnosed malignant glioma: Data from the glioma outcomes project. Journal of Neurosurgery 2003, 99:467.

15. Stupp R, Dietrich PY, Kraljevic SO, Pica A, Maillard I, Maeder P, Meuli R, Janzer R, Pizzolato G, Miralbell R, Porchet F, Regli L, De Tribolet $\mathrm{N}$, Mirimanoff RO, Leyvraz S: Promising survival for patients with newly diagnosed glioblastoma multiforme treated with concomitant radiation plus temozolomide followed by adjuvant temozolomide. Journal of Clinical Oncology 2002, 20:1375.

16. Chao ST, Barnett GH, Liu SW, Reuther AM, Toms SA, Vogelbaum MA, Videtic GMM, Suh JH: Five-year survivors of brain metastases: A single-institution report of 32 patients. International Journal of Radiation Oncology Biology Physics 2006, 66:80I.

17. Stupp R, Hegi ME, Mason WP, Bent MJ van den, Taphoorn MJ, Janzer RC, Ludwin SK, Allgeier A, Fisher B, Belanger K, Hau P, Brandes AA, Gijtenbeek J, Marosi C, Vecht CJ, Mokhtari K, Wesseling P, Villa S, Eisenhauer E, Gorlia T, Weller M, Lacombe D, Cairncross JG, Mirimanoff RO: Effects of radiotherapy with concomitant and adjuvant temozolomide versus radiotherapy alone on survival in glioblastoma in a randomised phase III study: 5-year analysis of the EORTC-NCIC trial. The Lancet Oncology 2009, 1 0:459.

18. Lagerwaard FJ, Levendag PC, Nowak PJCM, Eijkenboom WMH, Hanssens PEJ, Schmitz PIM: Identification of prognostic factors in patients with brain metastases: A review of 1292 patients. International Journal of Radiation Oncology Biology Physics 1999, 43:795.

19. Patchell RA, Tibbs PA, Walsh JW, Dempsey RJ, Maruyama Y, Kryscio RJ, Markesbery WR, Macdonald JS, Young B: A randomized trial of surgery in the treatment of single metastases to the brain. New England Journal of Medicine 1990, 322:494.

20. Jellinger K, Volc D, Grisold W: Multimodality treatment of malignant gliomas. Comparison of several adjuvant approaches. Zentralblatt fur Neurochirurgie 198I, 42:99.

21. Shapiro WR, Green SB, Burger PC, Mahaley MS, Selker RG, VanGilder JC, Robertson JT, Ransohoff J, Mealey J, Strike TA, Pistenmaa DA: Randomized trial of three chemotherapy regimens and two radiotherapy regimens in postoperative treatment of malignant glioma. Journal of Neurosurgery I989, 7 I: I-9.

22. Brada M, Hoang-Xuan K, Rampling R, Dietrich PY, Dirix LY, Macdonald D, Heimans JJ, Zonnenberg BA, Bravo-Marques JM, Henriksson R, Stupp R, Yue N, Bruner J, Dugan M, Rao S, Zaknoen S: Multicenter phase II trial of temozolomide in patients with glioblastoma multiforme at first relapse. Annals of Oncology 200I, I 2:259.

23. Randomized Trial of Procarbazine, Lomustine, and Vincristine in the Adjuvant Treatment of High-Grade Astrocytoma: A Medical Research Council Trial. J Clin Oncol 200I, I 9:509-5I8.

24. Yung WKA, Albright RE, Olson J, Fredericks R, Fink K, Prados MD, Brada M, Spence A, Hohl RJ, Shapiro W, Glantz M, Greenberg H, Selker RG, Vick NA, Rampling R, Friedman H, Phillips P, Bruner J, Yue N, Osoba D, Zaknoen S, Levin VA: A phase II study of temozolemide vs. procarbazine in patients with glioblastoma multiforme at first relapse. British Journal of Cancer 2000, 83:588.

25. Stupp R, Mason WP, Bent MJ Van Den, Weller M, Fisher B, Taphoorn MJB, Belanger K, Brandes AA, Marosi C, Bogdahn U, Curschmann J, Janzer RC, Ludwin SK, Gorlia T, Allgeier A, Lacombe D, Cairncross JG, Eisenhauer E, Mirimanoff RO: Radiotherapy plus concomitant 
and adjuvant temozolomide for glioblastoma. New England Journal of Medicine 2005, 352:987.

26. Lanzetta G, Campanella C, Rozzi A, Nappa M, Costa A, Fedele F, Innocenzi G, Gagliardi FM, Salvati M, Minniti G, Frati A, Frati L, Vecchione A: Temozolomide in Radio-chemotherapy Combined Treatment for Newly-diagnosed Glioblastoma Multiforme: Phase II Clinical Trial. Anticancer Research 2003, 23:5I59.

27. Thomas D, Brada M, Stenning S, Lantos P, Ironside J, Moss T, Whaley J, Bleehen NM, Roberts JT, Senanayake LFN, et al:: Randomized trial of procarbazine, lomustine, and vincristine in the adjuvant treatment of high-grade astrocytoma: A Medical Research Council Trial. Journal of Clinical Oncology 200I, 19:509.

28. Soffietti R, RudÃ R, Trevisan E: Brain metastases: Current management and new developments. Current Opinion in Oncology 2008, 20:676.

29. Greig NH: Chemotherapy of brain metastases: Current status. Cancer Treatment Reviews 1984, I I:I57.

30. Iwamoto FM, Omuro AM, Raizer JJ, Nolan CP, Hormigo AL, Lassman $A B$, Gavrilovic IT, Abrey LE: A phase II trial of vinorelbine and intensive temozolomide for patients with recurrent or progressive brain metastases. Journal of Neuro-Oncology 2008, 87:85.

31. Kosmas C, Tsakonas G, Mylonakis N: Treatment strategies in CNS metastases. Expert Opinion on Pharmacotherapy 2008, 9:2087.

32. Stupp R, Hegi ME, Gilbert MR, Chakravarti A: Chemoradiotherapy in malignant glioma: Standard of care and future directions. Journal of Clinical Oncology 2007, 25:4I 27.

33. Greig NH: Optimizing drug delivery to brain tumors. Cancer Treatment Reviews 1987, I 4: I.

34. Muldoon LL, Soussain C, Jahnke K, Johanson C, Siegal T, Smith QR, Hall WA, Hynynen K, Senter PD, Peereboom DM, Neuwelt EA: Chemotherapy delivery issues in central nervous system malignancy: A reality check. Journal of Clinical Oncology 2007, 25:2295.

35. Nies AT: The role of membrane transporters in drug delivery to brain tumors. Cancer Letters 2007, 254:II.

36. Vick NA, Khandekar JD, Bigner DD: Chemotherapy of brain tumors. The 'blood-brain barrier' is not a factor. Archives of Neurology 1977, 34:523.

37. Groothuis DR, Vick NA: Brain tumors and the blood-brain barrier. Trends in Neurosciences 1982, 5:232.

38. Essig M, Weber MA, Von Tengg-Kobligk H, Knopp MV, Yuh WTC, Giesel FL: Contrast-enhanced magnetic resonance imaging of central nervous system tumors: Agents, mechanisms, and applications. Topics in Magnetic Resonance Imaging 2006, 17:89.

39. Schneider G, Kirchin MA, Pirovano G, Colosimo C, Ruscalleda J, Korves $M$, Salerio I, Noce AL, Spinazzi A: Gadobenate dimeglumineenhanced magnetic resonance imaging of intracranial metastases: Effect of dose on lesion detection and delineation. Journal of Magnetic Resonance Imaging 200I, 1 4:525.

40. Levin VA, Landahl HD, Freeman Dove MA: The application of brain capillary permeability coefficient measurements to pathological conditions and the selection of agents which cross the blood brain barrier. Journal of Pharmacokinetics and Biopharmaceutics 1976, 4:499.

4I. Levin VA: Pharmacological principles of brain tumor chemotherapy. Advances in neurology 1976, 15:315.

42. Greig NH, Soncrant TT, Shetty HU, Momma S, Smith QR, Rapoport SI: Brain uptake and anticancer activities of vincristine and vinblastine are restricted by their low cerebrovascular permeability and binding to plasma constituents in rat. Cancer Chemotherapy and Pharmacology 1990, 26:263.

43. Begley DJ: ABC transporters and the blood-brain barrier. Current Pharmaceutical Design 2004, 10:1295.

44. Shapiro WR, Green SB, Burger PC, Selker RG, VanGilder JC, Robertson JT, Mealey J, Ransohoff J, Mahaley MS: A randomized comparison of intra-arterial versus intravenous with or without intravenous 5-fluorouracil, for newly diagnosed patients with malignant glioma. Journal of Neurosurgery 1992, 76:772-78|

45. Newton HB: Intra-arterial chemotherapy of primary brain tumors. Current Treatment Options in Oncology 2005, 6:519.

46. Nakagawa H, Fujita T, Izumoto S, Kubo S, Nakajima $Y$, Tsuruzono K, Kodama K, Higashiyama M, Doi O, Hayakawa T: Cis-diamminedichloroplatinum (CDDP) therapy for brain metastasis of lung cancer. I. Distribution within the central nervous system after intravenous and intracarotid infusion. Journal of Neuro-Oncology 1993, 16:61.
47. Zunkeler B, Carson RE, Olson J, Blasberg RG, DeVroom H, Lutz RJ, Saris SC, Wright DC, Kammerer W, Patronas NJ, Dedrick RL, Herscovitch $\mathrm{P}$, Oldfield EH: Quantification and pharmacokinetics of blood-brain barrier disruption in humans. Journal of Neurosurgery 1996, 85: 1056.

48. Rapoport SI: Osmotic opening of the blood-brain barrier: Principles, mechanism, and therapeutic applications. Cellular and Molecular Neurobiology 2000, 20:2 17.

49. Oliverio VT, Vietzke WM, Williams MK, Adamson RH: The absorption, distribution, excretion, and biotransformation of the carcinostatic I-(2-chloroethyl)-3-cyclohexyl-I-nitrosourea in animals. Cancer Research 1970, 30:1330.

50. Bender RA, Castle MC, Margileth DA, Oliverio VT: The pharmacokinetics of $[3 \mathbf{H}]$-vincristine in man. Clinical Pharmacology and Therapeutics 1977, 22:430.

5I. Slordal L, Jaeger R, Kjaeve J, Aarbakke J: Pharmacokinetics of 7. hydroxy-methotrexate and methotrexate in the rat. Pharmacology and Toxicology 1988, 63:81.

52. Preiss R, Baumann F, Regenthal R, Matthias M: Plasma kinetics of procarbazine and azo-procarbazine in humans. Anti-Cancer Drugs 2006, 17:75.

53. Rosenberg B: Fundamental studies with cisplatin. Cancer 1985 , 55:2303.

54. Newlands ES, Blackledge GRP, Slack JA, Rustin GJS, Smith DB, Stuart NSA, Quarterman CP, Hoffman R, Stevens MFG, Brampton MH, Gibson AC: Phase I trial of temozolomide (CCRG 81 045: $M$ and B 3983 I: NSC 362856). British Journal of Cancer 1992, 65:287.

55. Donelli MG, Zucchetti M, D'Incalci M: Do anticancer agents reach the tumor target in the human brain? Cancer Chemotherapy and Pharmacology 1992, 30:251.

56. Emerich DF, Dean RL, Marsh J, Pink M, Lafreniere D, Snodgrass $P$, Bartus RT: Intravenous cereport (RMP-7) enhances delivery of hydrophilic chemotherapeutics and increases survival in rats with metastatic tumors in the brain. Pharm Res 2000, I7:1212-1219.

57. Warren K, Gervais A, Aikin A, Egorin M, Balis FM: Pharmacokinetics of carboplatin administered with lobradimil to pediatric patients with brain tumors. Cancer Chemother Pharmacol 2004, 54:206-212

58. Thomas HD, Lind MJ, Ford J, Bleehen N, Calvert AH, Boddy AV: Pharmacokinetics of carboplatin administered in combination with the bradykinin agonist Cereport (RMP-7) for the treatment of brain tumours. Cancer Chemotherapy and Pharmacology 2000, 45:284.

59. Sarin H, Kanevsky AS, Fung SH, Butman JA, Cox RW, Glen D, Reynolds R, Auh S: Metabolically stable bradykinin B2 receptor agonists enhance transvascular drug delivery into malignant brain tumors by increasing drug half-life. Journal of Translational Medicine 2009, 7:33.

60. Warren K, Jakacki R, Widemann B, Aikin A, Libucha M, Packer R, Vezina G, Reaman G, Shaw D, Krailo M, Osborne C, Cehelsky J, Caldwell D, Stanwood J, Steinberg SM, Balis FM: Phase II trial of intravenous lobradimil and carboplatin in childhood brain tumors: A report from the Children's Oncology Group. Cancer Chemotherapy and Pharmacology 2006, 58:343.

6I. Dunkel IJ, Boyett JM, Yates A, Rosenblum M, Garvin JH Jr, Bostrom BC, Goldman S, Sender LS, Gardner SL, Li H, Allen JC, Finlay JL: High-dose carboplatin, thiotepa, and etoposide with autologous stem-cell rescue for patients with recurrent medulloblastoma. Journal of Clinical Oncology 1998, 16:222.

62. Dunkel IJ, Finlay JL: High-dose chemotherapy with autologous stem cell rescue for brain tumors. Critical Reviews in Oncology/ Hematology 2002, 41 : 197

63. Vargas F, Johnson JA: An Estimate Of Reflection Coefficients For Rabbit Heart Capillaries. J Gen Physiol 1964, 47:667-677.

64. Lipinski CA, Lombardo F, Dominy BW, Feeney PJ: Experimental and computational approaches to estimate solubility and permeability in drug discovery and development settings. Advanced Drug Delivery Reviews 1997, 23:3.

65. Langer R: Drug delivery and targeting. Nature 1998, 392:5-10.

66. Maeda H, Greish K, Fang J: The EPR effect and polymeric drugs: A paradigm shift for cancer chemotherapy in the 2 Ist century. Advances in Polymer Science 2006, 193:103.

67. Lengyel JS, Milne JLS, Subramaniam S: Electron tomography in nanoparticle imaging and analysis. Nanomedicine 2008, 3:125. 
68. Bootz A, Vogel V, Schubert D, Kreuter J: Comparison of scanning electron microscopy, dynamic light scattering and analytical ultracentrifugation for the sizing of poly(butyl cyanoacrylate) nanoparticles. European Journal of Pharmaceutics and Biopharmaceutics 2004, 57:369.

69. Veiseh O, Sun C, Fang C, Bhattarai N, Gunn J, Kievit F, Du K, Pullar $B$, Lee D, Ellenbogen RG, Olson J, Zhang M: Specific targeting of brain tumors with an optical/magnetic resonance imaging nanoprobe across the blood-brain barrier. Cancer Research 2009, 69:6200.

70. Sanchez De Juan B, Von Briesen H, Gelperina SE, Kreuter J: Cytotoxicity of doxorubicin bound to poly(butyl cyanoacrylate) nanoparticles in rat glioma cell lines using different assays. Journal of Drug Targeting 2006, 14:6/4.

7I. Sharma US, Sharma A, Chau RI, Straubinger RM: Liposome-mediated therapy of intracranial brain tumors in a rat model. Pharm Res 1997, 14:992-998.

72. Siegal T, Horowitz A, Gabizon A: Doxorubicin encapsulated in sterically stabilized liposomes for the treatment of a brain tumor model: biodistribution and therapeutic efficacy. J Neurosurg 1995, 83:1029-1037.

73. Sarin H, Kanevsky A, Wu H, Brimacombe K, Fung S, Sousa A, Auh S, Wilson C, Sharma K, Aronova M, Leapman R, Griffiths G, Hall M: Effective transvascular delivery of nanoparticles across the blood-brain tumor barrier into malignant glioma cells. Journal of Translational Medicine 2008, 6:80.

74. Sarin H, Kanevsky A, Wu H, Sousa A, Wilson C, Aronova M, Griffiths G, Leapman R, Vo H: Physiologic upper limit of pore size in the blood-tumor barrier of malignant solid tumors. Journal of Translational Medicine 2009, 7:5I.

75. Fenstermacher JD, Johnson JA: Filtration and reflection coefficients of the rabbit blood-brain barrier. The American journal of physiology 1966, 21 I:34I.

76. Brightman MW, Reese TS: Junctions between intimately apposed cell membranes in the vertebrate brain. Journal of Cell Biology 1969, 40:648.

77. Brightman MW, Klatzo I, Olsson Y, Reese TS: The blood-brain barrier to proteins under normal and pathological conditions. J Neurol Sci 1970, 10:215-239.

78. Bruns RR, Palade GE: Studies on blood capillaries. I. General organization of blood capillaries in muscle. Journal of Cell Biology 1968, 37:244-276.

79. Michel CC, Curry FE: Microvascular permeability. Physiological Reviews 1999, 79:703-761.

80. Folkman J: Tumor angiogenesis: therapeutic implications. New England Journal of Medicine 197I, 285: I I 82.

81. Folkman J, Klagsbrun M: Angiogenic factors. Science 1987, 235:442.

82. Jain RK: Transport of molecules across tumor vasculature. Cancer Metastasis Rev 1987, 6:559-593.

83. Roberts WG, Palade GE: Neovasculature induced by vascular endothelial growth factor is fenestrated. Cancer Res 1997, 57:765-772.

84. Vick NA, Bigner DD: Microvascular abnormalities in virallyinduced canine brain tumors. Structural bases for altered blood-brain barrier function. I Neurol Sci 1972, 17:29-39.

85. Hashizume H, Baluk P, Morikawa S, McLean JW, Thurston G, Roberge $S$, Jain RK, McDonald DM: Openings between defective endothelial cells explain tumor vessel leakiness. Am J Pathol 2000, 156:1363-1380.

86. Schlageter KE, Molnar P, Lapin GD, Groothuis DR: Microvessel organization and structure in experimental brain tumors: Microvessel populations with distinctive structural and functional properties. Microvascular Research 1999, 58:312-328.

87. Satchell SC, Braet F: Glomerular endothelial cell fenestrations: an integral component of the glomerular filtration barrier. Am J Physiol Renal Physiol 2009, 296:F947-956.

88. Sousa AA, Aronova MA, Wu H, Sarin H, Griffiths GL, Leapman RD: Determining molecular mass distributions and compositions of functionalized dendrimer nanoparticles. Nanomedicine 2009, 4:391-399.

89. Asotra K, Ningaraj N, Black KL: Measurement of Blood-Brain and Blood-Tumor Barrier Permeabilities with [14C]Labeled Tracers. 2003, 89:177-190.
90. Hasegawa $\mathrm{H}$, Ushio $\mathrm{Y}$, Hayakawa $\mathrm{T}$ : Changes of the blood-brain barrier in experimental metastatic brain tumors. Journal of Neurosurgery 1983, 59:304-310.

91. Molnar P, Blasberg RG, Horowitz M, Smith B, Fenstermacher J: Regional blood-to-tissue transport in RT-9 brain tumors. Journal of Neurosurgery 1983, 58:874-884.

92. Monsky WL, Carreira CM, Tsuzuki Y, Gohongi T, Fukumura D, Jain RK: Role of host microenvironment in angiogenesis and microvascular functions in human breast cancer xenografts: Mammary fat pad versus cranial tumors. Clinical Cancer Research 2002, 8: 1008-1013.

93. Tofts PS, Brix G, Buckley DL, Evelhoch JL, Henderson E, Knopp MV, Larsson HB, Lee TY, Mayr NA, Parker GJ, Port RE, Taylor J, Weisskoff RM: Estimating kinetic parameters from dynamic contrast-enhanced T(I)-weighted MRI of a diffusable tracer: standardized quantities and symbols. J Magn Reson Imaging 1999, 10:223-232.

94. Ferrier MC, Sarin H, Fung SH, Schatlo B, Pluta RM, Gupta SN, Choyke PL, Oldfield EH, Thomasson D, Butman JA: Validation of dynamic contrast-enhanced magnetic resonance imaging-derived vascular permeability measurements using quantitative autoradiography in the $\mathbf{R} \mathbf{2} 2$ rat brain tumor model. Neoplasia 2007, 9:546-555.

95. Haacke EM, Brown RW, Thompson MR, Venkatesan M: Magnetic Resonance Imaging: Physical Principles and Sequence Design New York: Wiley; 1999.

96. Pries AR, Secomb TW, Gaehtgens P: The endothelial surface layer. Pflugers Archiv European Journal of Physiology 2000, 440:653.

97. Weinbaum S, Zhang X, Han Y, Vink H, Cowin SC: Mechanotransduction and flow across the endothelial glycocalyx. Proceedings of the National Academy of Sciences of the United States of America 2003, 100:7988-7995.

98. Squire JM, Chew M, Nneji G, Neal C, Barry J, Michel C: Quasi-Periodic Substructure in the Microvessel Endothelial Glycocalyx: A Possible Explanation for Molecular Filtering? Journal of Structural Biology 200I, 136:239-255.

99. Curry FE, Michel CC: A fiber matrix model of capillary permeability. Microvasc Res 1980, 20:96-99.

100. Chappell D, Jacob M, Paul O, Rehm M, Welsch U, Stoeckelhuber M, Conzen P, Becker BF: The Glycocalyx of the Human Umbilical Vein Endothelial Cell: An Impressive Structure Ex Vivo but Not in Culture. Circ Res 2009, 104:1313-1317.

I0I. Muldoon LL, Nilaver G, Kroll RA, Pagel MA, Breakefield XO, Chiocca EA, Davidson BL, Weissleder R, Neuwelt EA: Comparison of intracerebral inoculation and osmotic blood-brain barrier disruption for delivery of adenovirus, herpesvirus, and iron oxide particles to normal rat brain. American Journal of Pathology 1995, 147: 1840.

102. Nilaver G, Muldoon LL, Kroll RA, Pagel MA, Breakefield XO, Davidson $B L$, Neuwelt EA: Delivery of herpesvirus and adenovirus to nude rat intracerebral tumors after osmotic blood-brain barrier disruption. Proceedings of the National Academy of Sciences of the United States of America 1995, 92:9829.

103. Adamson RH: Permeability of frog mesenteric capillaries after partial pronase digestion of the endothelial glycocalyx. Journal of Physiology 1990, 428: I- 13.

104. Henry CBS, Duling BR: Permeation of the luminal capillary glycocalyx is determined by hyaluronan. Am J Physiol 1999 , 277: $\mathrm{H} 508-\mathrm{H} 5 \mid 4$

105. Lossinsky AS, Shivers RR: Structural pathways for macromolecular and cellular transport across the blood-brain barrier during inflammatory conditions. Review. Histology and Histopathology 2004, 19:535

106. Campbell RB, Fukumura D, Brown EB, Mazzola LM, Izumi Y, Jain RK, Torchilin VP, Munn LL: Cationic charge determines the distribution of liposomes between the vascular and extravascular compartments of tumors. Cancer Research 2002, 62:683 I-6836.

107. Dellian M, Yuan F, Trubetskoy VS, Torchilin VP, Jain RK: Vascular permeability in a human tumour xenograft: Molecular charge dependence. British Journal of Cancer 2000, 82:15|3-I5|8.

108. Saltzman WM, Radomsky ML, Whaley KJ, Cone RA: Antibody diffusion in human cervical mucus. Biophysical Journal 1994, 66:508.

109. Kalofonos HP, Grivas PD: Monoclonal antibodies in the management of solid tumors. Current Topics in Medicinal Chemistry 2006, 6: 1687. 
I 10. Li J, Piehler LT, Qin D, Baker JR Jr, Tomalia DA, Meier DJ: Visualization and characterization of poly(amidoamine) dendrimers by atomic force microscopy. Langmuir 2000, 16:5613.

III. Müller R, Laschober C, Szymanski WW, Allmaier G: Determination of molecular weight, particle size, and density of high number generation PAMAM dendrimers using MALDITOF-MS and nES-GEMMA. Macromolecules 2007, 40:5599.

II2. Jackson CL, Chanzy HD, Booy FP, Drake BJ, Tomalia DA, Bauer BJ, Amis E): Visualization of dendrimer molecules by transmission electron microscopy (TEM): Staining methods and cryoTEM of vitrified solutions. Macromolecules 1998, 31:6259-6265.

I I3. Soo Choi H, Liu W, Misra P, Tanaka E, Zimmer JP, Itty Ipe B, Bawendi MG, Frangioni JV: Renal clearance of quantum dots. Nat Biotechnol 2007, 25: I 165-1 I 170

II4. Roberts HC, Roberts TPL, Brasch RC, Dillon WP: Quantitative measurement of microvascular permeability in human brain tumors achieved using dynamic contrast-enhanced MR imaging: Correlation with histologic grade. American Journal of Neuroradiology 2000, 21:891.

I I5. Jain R, Ellika SK, Scarpace L, Schultz LR, Rock JP, Gutierrez J, Patel SC, Ewing J, Mikkelsen T: Quantitative estimation of permeability surface-area product in astroglial brain tumors using perfusion CT and correlation with histopathologic grade. American Journal of Neuroradiology 2008, 29:694.

II6. Lutty GA: The acute intravenous toxicity of biological stains, dyes, and other fluorescent substances. Toxicology and Applied Pharmacology 1978, 44:225-249.

1 17. Herce HD, Garcia AE: Cell Penetrating Peptides: How Do They Do It? Journal of Biological Physics 2008: I-I2.

1 18. Thaler S, Haritoglou C, Choragiewicz TJ, Messias A, Baryluk A, May CA, Rejdak R, Fiedorowicz M, Zrenner E, Schuettauf F: In vivo toxicity study of rhodamine $\mathbf{6 G}$ in the rat retina. Investigative Ophthalmology and Visual Science 2008, 49:2I 20.

119. Hobbs SK, Monsky WL, Yuan F, Roberts WG, Griffith L, Torchilin VP, Jain RK: Regulation of transport pathways in tumor vessels: role of tumor type and microenvironment. Proc Natl Acad Sci USA 1998, 95:4607-46I2.

120. Yuan F, Dellian M, Fukumura D, Leunig M, Berk DA, Torchilin VP, Jain RK: Vascular permeability in a human tumor xenograft: Molecular size dependence and cutoff size. Cancer Research 1995, 55:3752.

121. Mecke A, Majoros IJ, Patri AK, Baker JR Jr, Banaszak Holl MM, Orr BG: Lipid bilayer disruption by polycationic polymers: The roles of size and chemical functional group. Langmuir 2005, 21:10348.

122. Lee CC, Gillies ER, Fox ME, Guillaudeu SJ, Frechet JMJ, Dy EE, Szoka FC: A single dose of doxorubicin-functionalized bow-tie dendrimer cures mice bearing C-26 colon carcinomas. Proceedings of the National Academy of Sciences of the United States of America 2006, 103:16649.

123. Greenfield RS, Kaneko T, Daues A, Edson MA, Fitzgerald KA, Olech LJ, Grattan JA, Spitalny GL, Braslawsky GR: Evaluation in vitro of adriamycin immunoconjugates synthesized using an acidsensitive hydrazone linker. Cancer Research 1990, 50:6600.

124. Moriyama Y, Maeda M, Futai M: Involvement of a non-proton pump factor (possibly Donnan-type equilibrium) in maintenance of an acidic pH in lysosomes. FEBS Letters 1992, 302:18.

125. Kono K, Kojima C, Hayashi N, Nishisaka E, Kiura K, Watarai S, Harada A: Preparation and cytotoxic activity of poly(ethylene glycol)-modified poly(amidoamine) dendrimers bearing adriamycin. Biomaterials 2008, 29:1664.

126. Vaupel P: Blood flow and metabolic microenvironment of brain tumors. Journal of Neuro-Oncology 1994, 22:261.

127. Carmichael J, DeGraff WG, Gazdar AF: Evaluation of a tetrazolium-based semiautomated colorimetric assay: Assessment of chemosensitivity testing. Cancer Research 1987, 47:936.

128. Jeansson M, Bjorck K, Tenstad O, Haraldsson B: Adriamycin alters glomerular endothelium to induce proteinuria. Journal of the American Society of Nephrology 2009, 20: II 4.

129. Barth RF: Rat brain tumor models in experimental neurooncology: The 9L, C6, T9, F98, RG2 (D74), RT-2 and CNS-I gliomas. Journal of Neuro-Oncology 1998, 36:91-102.

130. Xie Q, Thompson R, Hardy K, DeCamp L, Berghuis B, Sigler R, Knudsen B, Cottingham S, Zhao P, Dykema K, Cao B, Resau J, Hay R, Woude G Vande: A highly invasive human glioblastoma pre- clinical model for testing therapeutics. Journal of Translational Medicine 2008, 6:77.

13I. Yang W, Barth RF, Wu G, Tjarks W, Binns P, Riley K: Boron neutron capture therapy of EGFR or EGFRvIII positive gliomas using either boronated monoclonal antibodies or epidermal growth factor as molecular targeting agents. Applied Radiation and Isotopes 2009, 67:S328-S33I.

132. Arifin DY, Lee KYT, Wang CH: Chemotherapeutic drug transport to brain tumor. Journal of Controlled Release 2009, 137:203.

133. Hall WA: Convection-enhanced delivery: Neurosurgical issues. Current Drug Targets 2009, 10:126.

134. Yang W, Barth RF, Wu G, Huo T, Tjarks W, Ciesielski M, Fenstermaker RA, Ross BD, Wikstrand CJ, Riley KJ, Binns PJ: Convection enhanced delivery of boronated EGF as a molecular targeting agent for neutron capture therapy of brain tumors. Journal of Neuro-Oncology 2009 in press.

135. Alam F, Soloway AH, Bapat BV, Barth RF, Adams DM: Boron compounds for neutron capture therapy. Basic life sciences 1989 , 50: 107.

136. Capala J, Barth RF, Bendayan M, Lauzon M, Adams DM, Soloway AH, Fenstermaker RA, Carlsson J: Boronated epidermal growth factor as a potential targeting agent for boron neutron capture therapy of brain tumors. Bioconjugate Chemistry 1996, 7:7.

137. Yang W, Wu G, Barth RF, Swindall MR, Bandyopadhyaya AK, Tjarks W, Tordoff K, Moeschberger M, Sferra TJ, Binns PJ, Riley KJ, Ciesielski MJ, Fenstermaker RA, Wikstrand CJ: Molecular targeting and treatment of composite EGFR and EGFRvIII-positive gliomas using boronated monoclonal antibodies. Clinical Cancer Research 2008, 14:883.
Publish with Bio Med Central and every scientist can read your work free of charge

"BioMed Central will be the most significant development for disseminating the results of biomedical research in our lifetime."

Sir Paul Nurse, Cancer Research UK

Your research papers will be:

- available free of charge to the entire biomedical community

- peer reviewed and published immediately upon acceptance

- cited in PubMed and archived on PubMed Central

- yours - you keep the copyright
BioMedcentral 